\title{
Living Environment as Location Decision Factor for Manufacturing Enterprises
}

\author{
Kaarel Kilvits \\ Tallinn University of Technology, Tallinn, Estonia
}

\begin{abstract}
Space is not homogeneous. Different economic activities take place in different locations. There are many factors which affect the location of manufacturing enterprises. These include raw materials, land, labor supply, markets, transport/communications, energy, capital, markets, government policy, etc.. While previously cost and profit were the main determinants in the traditional location theory, nowadays, soft factors such as "quality of life” (housing, environment and infrastructure), “image” of places or “private” reasons are important determinants. A high-quality living environment is an increasingly important location decision factor first of all for companies who need to attract young and talented educated workers. Highly skilled workers/specialists, as a rule, have a well-kept and demanding family for the living conditions. They are willing to live and work only in a region where there is a good housing, environment and infrastructure. Or move to such place from a place that does not satisfy them. Location priorities are also believed to change according to the function of the site (headquarter needs international airport, central city location, hotels, restaurants; research and development unit needs universities, science parks; manufacture and distribution need good transportation system). The main goal of this paper is to summarize the objectives and experiences of knowledge applied by different agents and to study alternatives and opportunities in this process. One task of the current paper is to clarify different concepts with regard to residential attractiveness, urban development and housing policy to formulate research questions for further empirical research.
\end{abstract}

Keywords: housing, industry, delocalization, relocation

\section{Introduction}

The economic landscape has undergone many significant changes in the last few decades, the most extensive of which is globalization. In its wake certain kinds of economic activity have become more and more easily dispersed across space, and distance matters less in the transfer of goods and people. At a political and economic level, globalization is the process of denationalization of markets, politics and legal systems, i.e., the rise of the so-called global economy. Globalization refers to an extension beyond national borders of the same market forces that have operated for centuries at all levels of human economic activity. It means that world trade and financial markets are becoming more and more integrated.

At a business level, we talk of globalization when companies decide to take part in the emerging global

Kaarel Kilvits, Ph.D., Professor, Department of Public Economy, Tallinn University of Technology.

Correspondence concerning this article should be addressed to Kaarel Kilvits, Akadeemia tee 3, 12618 Tallinn, Estonia. E-mail: kaarel.kilvits@tseba.ttu.ee. 
economy and establish themselves in foreign markets. A major aspect of economic globalization is the combination of free trade and free movement of capital. Economic, technological, political etc., processes change the world into an integral whole. The type of business that dominates today's global economic system operates on the basis of finding the cheapest production (in particular labor) cost. During the past 15-20 years delocalization of labor-intensive industries-international relocation, the shifting of work to low-cost (low-wage) countries — has been a usual (dominating) development in world manufacturing.

The turbulent transformation of economy and society looks to continue. Growing integration of markets, radical new technologies, increasing knowledge intensity of human activity—all point to the emergence of an immensely complex world. Problems are arising in developed countries and also in developing countries. Due to changes in the markets, consumer preferences, environmental regulations, technological progress and so on, firms are constantly adjusting to new situations. This process very often also has a spatial dimension.

While previously cost and profit were the main determinants in the traditional location theory, nowadays, soft factors such as "quality of life" (housing, environment and infrastructure), "image” of places or "private" reasons are important determinants. A high-quality living environment is an increasingly important location decision factor first of all for companies who need to attract young and talented educated workers.

The main starting points of this paper are: (1) living environment depends on location of industries; and (2) location of industries in turn depends on living environment. The paper seeks to cover the living environment as location decision factor for manufacturing enterprises. The main goal of this paper is to summarize the objectives and experiences of knowledge applied by different agents. The research questions have been formulated for further empirical studies.

\section{Modern Industry Location Theories}

Space is not homogeneous. Different economic activities take place in different locations. According to McCann (2002, p. 3), spatial economic costs can be divided into two types: (1) those that are incurred at a point in space; and (2) those that are incurred in the overcoming of space itself. For example, local labor prices and land costs fall into the former category, whereas transportation costs and telecommunication costs fall into the latter. Both individual changes and changes in relationship between these place-specific costs and transportation costs have impacts on the optimum location of the firm.

A location factor describes the attractiveness of a production location for a trade settlement in the economic life. Location factors are the whole of factors, which affect an enterprise in the choice of a location. There are many factors which affect the location of industry. These include raw materials, land, labor (supply, wages and benefits, skills, education/trainability, unionization/right-to-work, etc.), markets (type of demand, size of market, stability of market, income or economic strength, etc.), transport/communications, energy, capital, government policy, etc..

The problem of locating industry was very actual already at the end of the 19th century when the industrial revolution was well established, and development of rail transport, energy, telecommunications and urban growth provided more options for distributing firms and components of the manufacturing process. With the publication of “Über den Standort der Industrie” (Theory of the Location of Industries) in 1909, Alfred Weber put forth the first developed general theory of industrial location. His model took into account several spatial factors 
for finding the optimal location and minimal cost for manufacturing plants. Industry location theories have been lately thoroughly studied by Dunn, Poleske, and Xiadong (2004), earlier Parr (2002), Krugman (1995), Storper and Walker (1989) and by many other economists.

Theories respecting the location of firms (Parr, 2002, pp. 32-82) summarize the framework known as a central place theory, built by early location theorists like Weber, Christaller, and Lösch. The central place theory carries the assumption that population and resources are uniformly distributed over a homogenous plane, firms have free entry into the market, and perfect competition exists. In this model, production factors (labor and capital) and transportation costs represent the keys to understanding firm location: firms locate in such a way as to maximize profits. Yet, even with the added complexities of hexagonally-shaped markets to capture the entire market space and a "nested" hierarchy of variably-sized central places, the central place theory "cannot be regarded as a general theory of the urban system” (Parr, 2002, p. 79).

Krugman (1995) offers four explanations of firm location. First, the notion of social physics is helpful in constructing economic relationships that are analogous to observed laws of physics. For example, firms will locate at points of high market potential, where the computation of market potential is some measure of market access divided by distance (the gravity model). Secondly, cumulative causation suggests a circular relationship whereby a region attracts firms whose presence attracts other firms, who attract still other firms, and so on. This is similar to the alternative location theory of clustering. Third, positive local externalities "promote concentration of production”, and analysis of these externalities can provide insights into optimum city size. Finally, the land rents theory of von Thünen assumes a gradient of land values as one moves away from an urban centre. This model explains "centrifugal" forces quite well, but it has little explanatory power with respect to the existence of economic centres (Krugman, 1995, pp. 38-55).

In the second half of the 20th century, alternative theories of location emerged. The principal features of these attempts to explain firm location are emphasis on the importance of spatial diffusion and consideration of political and social interactions. In addition, as Storper and Walker (1989, p. 70) argue, "the basic patterns of industry location and regional growth can be processed endogenous to capitalist industrialization, rather than exogenous placements of resources and consumers". In other words, firms can "create economic space”. This contrasts with the neoclassical theories, in which firm location occurs more or less as a response to economic conditions in a region.

Similar industries will tend to grow together in particular regions (automobile industry in Detroit; the high-tech agglomerations in Silicon Valley, California). Such agglomerations owe their self-perpetuation largely to social and economic factors. The growing cluster attracts sellers, merchant intermediaries, and labor from afar. Firms of different types will cluster together in an urban region and will form an inter-reliance as the size of the region becomes large.

Firms may relocate and decentralize in order to separate from the "dwindling profits" of an over-interested core and to "extend into new growth peripheries” (Storper \& Walker, 1989, p. 88). Firms are also motivated by the prospect of cheaper labor pools and rents. Such movements may be linked with the product cycle, which can lead to broad decentralization.

Where economic activity will locate in the future is one of the most important and challenging questions in economics. Progress in technology, changes in demand and moves towards a liberal economic policy and 
international economic integration create new challenges for economists, policy-makers and business executives.

According to McCann (2002), Hayter (1997), and Machlup (1967), a division into three types of location theory may be made: a neoclassical, a institutional and a behavioral approach.

The neoclassical approach (McCann, 2002, pp. 112-114), which is derived from the standard classical economic theory, focuses on cost-minimizing and profit-maximizing theories. There may be significant relocation costs. Relocation costs may be the direct costs of moving, as well as the search and information costs of finding new markets, labor, suppliers and deliverers, and so on. A move to another geographical market is to a certain extent similar to a start-up, with large investments and uncertain revenues. There may be also a substantial amount of capital inertia. For instance, many existing buildings and other equipment at the old location may already be written off, and still be operational at low costs.

In the modern globalised economy we have to look not only at the behavior of the firm, but also at the social and cultural context in which this behavior is embedded. Institutional approaches (McCann, 2002, pp. 117-118) have dominated the field so far. Firms have to negotiate with deliverers and suppliers, local, regional or national governments, labor unions and other institutions, about prices, wages, taxes, subsidies, infrastructure and other key factors in production process of the firm. Locational behavior is the result of all these negotiations. The implication of this view is that the geography of enterprise is more suited to large corporations, which have more negotiating power, and are able to exert a substantial influence upon their environment, whereas small firms usually have to accept the restrictions and constraints imposed upon by their environment. Regional systems are important contexts for firms' growth. There are two types of institutions that are important for (re)location behavior of small and medium-sized enterprises: governments and real-estate market. Governmental facilitating factors are, for instance, infrastructure, zoning, subsidies and tax reductions.

The behavioral approach (McCann, 2002, pp. 114-116) is based on more realistic notations of limited information and bounded rationality. Here, optimizing behavior is replaced by "satisficing” behavior. Apart from the decision-making process, which is made explicit, there are four key elements in behavioral location theory: (1) the role of limited information; (2) the ability to use information; (3) perception and mental maps; and (4) uncertainty. More distant locations are less well known and therefore it is likely that nearer locations are chosen more frequently. Distant locations are more difficult to imagine than nearer places. There is a strong distance decay in mental maps, which is of course partly related to the amount of information, but also to the perceived attractiveness of the place. Firms face uncertainty, not only because they have a knowledge gap or they are unable to digest the available information, but also because investment decisions are based on anticipated future situations, which are by definition uncertain. Anticipating the future for other locations that are not familiar adds to the uncertainty.

Due to changes in the markets, consumer preferences, environmental regulations, technological progress and so on, firms are constantly adjusting to new situations. This process very often also has a spatial dimension (McCann, 2002, p. 110).

Traditionally, the spatial distribution of activities is explained using a model of the product's life cycle (Federal Planning Bureau, 2000). According to this model, activities are transferred to countries with lower wage costs at that stage of the product's life cycle where standardization occurs. The cycle begins with the product's design, followed by its entry into the market, expansion, export and, finally, foreign investments which may lead 
to relocation. Production abroad is market-oriented at first, but production costs (including wage costs) play an ever increasing role as the production process undergoes standardization.

Firm relocation differs from firm location because it explicitly takes account of the fact that one location is substituted for another. The firm has history, and this history is likely to have an influence on the locational outcome of the process. This locational outcome is therefore conditional (McCann, 2002, p. 111).

Another way to look at this is to separate the relocalization process into two sequential steps (McCann, 2002, p. 111): (1) the decision to move; and (2) conditional upon a move, to relocate to another location. A similar distinction is between push and pull factors of migration. Push factors are things that are unfavorable about the area that one lives in, and pull factors are things that attract one to another area.

The predisposition of manufacturing industry towards delocalization is a result of operation of three factor groups-the so-called push-factors, pull-factors and keep-factors of delocalization (Ženka \& Cadil, 2009; van Dijk \& Pellenberg, 1999).

Push-factors are motives leading firms to leave their locality (Ženka \& Cadil, 2009; Pen, 1999). They represent a set of regional comparative disadvantages forcing firms to delocalize. Pull-factors are comparative advantages of potential target regions for delocalization. Considering operation of push- and pull-factors, it is possible to categorize the delocalization, by the prevailing motives of companies' displacement as cost-oriented (most often driven by labor cost reduction), market-oriented (capturing new markets), and resource-oriented (qualified labor force, suppliers, mineral resources, etc.).

Keep-factors favor firm continuance in the current location (financial and organizational intensity of possible delocalization; relations with suppliers, etc.).

The increased importance of scale advantages and greater spatial flexibility have led to a more complicated pattern of spatial activity distribution. Companies are thinking increasingly in terms of multinational networks that no longer duplicate activities in various countries, but integrate them across several countries. In today's economy, this allows that both research and a part of production—via subcontracting, for example—-take place either partially or totally in different countries. Relocation is inevitable in order to come to a global supply chain. Particularly multinational companies (MNCs) are taking advantage of this by concentrating their activities in a limited number of outlets (Federal Planning Bureau, 2000).

According to Ferdows (1997), firms expand internationally for a variety of reasons: (1) reduce direct and indirect costs; (2) reduce capital risks; (3) reduce taxes; (4) reduce logistics costs; (5) overcome tariff barriers; (6) provide better customer service; (7) spread foreign exchange risks; (8) build alternative supply sources; (9) pre-empt potential competitors; (10) learn from local suppliers, foreign customers; foreign competitors, and foreign research centres; and (11) attract talent globally. According to Mohamed and Youssef (2004) these reasons can be broadly classified into marketing factors, barriers to trade, cost factors, investment climate, and general categories.

According to Mohamed and Youssef (2004) many studies have shown that transferring production to foreign locations is a viable alternative to lowering production costs, entry into foreign markets, and avoiding import (export) restrictions to gain competitive advantage in domestic and global markets. MNCs are willing to locate their facilities in any part of the world where they can obtain cheap labor, more reliable materials, parts, subassemblies, vendors, and governments that provide financial incentives. A long time ago, McDonald (1986) 
claimed that many manufacturing companies are willing to locate their facilities in any part of the world where they can obtain cheap labor, more reliable materials, parts, subassemblies, vendors, and governments which provide financial incentives.

Where, in the past, a firm relocated whole production process by shutting down operations in one location and opening the same operations in another location, delocalization involves moving components of the firm and/or its production processes outside its operations. Delocalization is generally being undertaken by MNCs focusing on changing the supply chain. This drives inter-firm collaboration around global, decentralized and decoupled supply chains where each node of the value creation process is self-contained, self-directed and in many cases external to the equity structure of the MNC.

\section{Housing, Environment and Infrastructure as Location Decision Factor}

While previously cost and profit were the main determinants in the traditional location theory, nowadays, soft factors such as "quality of life” (housing, environment and infrastructure), "image” of places or "private” reasons are important determinants. The climate, low crime, educational system, cost of living, quality and cost of housing, quality of air and water, recreation facilities, etc. (all modern living and work environment) are very important for potential high-technology investors and skilled labor. Knowledge workers prefer places with a diverse range of outdoor recreational activities.

Good living environment means that local authorities are responsible for land use planning and building supervision. Participation in local affairs and the voice of community members are safeguarded both in the preparation of plans and in decisions. Municipal housing policy, public building, the maintenance of the transport infrastructure, public transport, parks and outdoor areas also effect the living environment.

Highly skilled workers/specialists, as a rule, have a well-kept and demanding family for the living conditions. They are willing to live and work only in a region where there is a good infrastructure. Or move to such place from a place that does not satisfy them. A high-quality living environment is an increasingly important location decision factor first of all for companies which need to attract young and talented educated workers.

According to McCann (2002), Hayter (1997) and Machlup (1967), neoclassical approach focuses mostly on the location theory and centres its analysis on profit maximization strategies and minimization of costs (transportation costs, human resources costs and external economies). Institutional approach states that it is important to consider not just the firm's search for an appropriate location but also the institutional milieu which is part of (clients, suppliers, commercial associations, regional systems, the government and other firms). But behavioral approach focuses on situations of uncertainty and lack of information.

Most important behavioral factors are (Fernandes, Ferreira, \& Marques, 2010): (1) Founder decides to live in that locality; (2) Employees wish to live in that locality, (3) Good (high-quality affordable) housing conditions (prices, size, etc.); (4) Recreational and leisure opportunities; (5) Climate in the region; (6) Cost of the land; (7) Quality of air and water; and (8) Good educational system and all infrastructure.

The business sector is a fundamental determinate of a firm's location choice (Cohen, 2000). Manufacturing companies, for example, need to balance proximity to end-user markets against supplier resources.

Location priorities are also believed to change according to the function of the site (Cohen, 2000):

- Headquarters' location priorities include: (1) accessible international air service; (2) high-end hotels, 
restaurants, entertainment, cultural events, major league sport team/stadium with skyboxes to facilitate heavy inter-company face-to-face interaction; (3) professional support services; (4) good choice of office space or availability of land to built-to-suit; (5) diverse professional employee base; (6) attractive housing for executives, affordable housing for managers; (7) support staff within reasonable commute; (8) strong educational system for employee's children; (9) continuing adult education; and (10) central city locations likely. Cost sensitivity is less important than availability of key requirements;

- Research and development requires: (1) proximity to concentration of universities and science parks; (2) clusters of highly educated workers, or alternatively, lifestyle amenities that are attractive to this pool of talent. Some R\&D firms want control over their physical environment, to buffer company from nosy neighbors and to prevent the sharing of secrets by employees. Cost sensitivity is less important than the availability of talent and other requirements. However, R\&D may be more sensitive to cost than headquarters;

- Back office requires: (1) state-of-the-art telecommunications capacity; (2) affordable housing costs; (3) high-quality labor force with technical skills; (4) good schools for employee recruitment and their children; and (5) on-going available adult education and training. A back office is sensitive to cost of real estate, telecommunications, housing, and taxes. Location preferred outside main centres;

- Manufacture and distribution firm needs to be near major interstates, they need strong utility systems (electric, water, wastewater, gas, etc.). These firms also want a well-educated workforce and strong specialized training programs. Manufacturing and distributing firms are sensitive to housing costs, taxes, and utility rates.

Location requirements differ depending on the company's product maturity. A cost structure that works well at the early stages of product development will not necessarily support its competitiveness as the product matures (Cohen, 2000). At the R\&D phase company may be less sensitive to real estate costs but quite sensitive to the availability of sophisticated labor markets and talent. Later business will become more cost sensitive and low-cost regions at the periphery or even offshore locations may provide more cost advantages.

A company's competitive strategy determines the location choice (Cohen, 2000). Companies trying to reposition itself in a significant way do not necessarily choose the lowest cost locations.

If living environment is satisfactory only in some regions, investment-intensive new high-technology, high value-added jobs are created only there. And only top specialists and skilled workers in these regions will benefit from these, not "ordinary people" in other regions. Such structural changes may even increase economic, social, regional etc., stratification.

\section{Conclusions}

While previously cost and profit were the main determinants in the traditional location theory, nowadays, soft factors such as "quality of life" (housing, environment and infrastructure), "image” of places or "private" reasons are important determinants. A high-quality living environment is an increasingly important location decision factor first of all for companies who need to attract young and talented educated workers.

Highly skilled workers/specialists, as a rule, have a well-kept and demanding family for the living conditions. They are willing to live and work only in a region where there is a good infrastructure. Or move to such place from a place that does not satisfy them.

Location priorities are also believed to change according to the function of the site: headquarter needs 
international airport, central city location, hotels, restaurants; research and development unit needs universities, science parks; manufacture and distribution need good transportation system.

If living environment is satisfactory only in some regions, investment-intensive new high-technology, high value-added jobs are created only there. And only top specialists and skilled workers in these regions will benefit from these, not "ordinary people” in other regions. Such structural changes may even increase economic, social, regional etc., stratification.

\section{References}

Cohen, N. (2000). Business location decisions-making and the cities: Bringing companies back. Washington, D.C.: The Brookings Institution: April.

Dijk, J. Van, \& Pellenberg, P. H. (1999). Firms spatial dynamics of firm behavior (p. 262). Utrecht/Groningen: KNAG/FRW RUG.

Dunn, T. P., Polenske, K., \& Xiaodong, W. (2004). Describing industry location: Theory and empirical evidence. Retrieved January 6, 2012, from http://www.dspace.mit.edu/bitstream/handle/1721.1/55899/11-481JSpring-2006 /NR/rdonlyres/Urban-Studies -and-Planning/ 11-481JSpring-2006/dunn.pdf.txt?sequence $=120$

Federal Planning Bureau. (2000). Relocation, an element of industrial dynamics. Synthesis Report. Brussels.

Ferdows, K. (1997). Making the most of foreign factories. Harvard Business Review, March, 73-88.

Fernandes, C., Ferreira, J., \& Marques, C. (2010). Location theories influence on technology based entrepreneurs: A multidimensional Approach. AGSE.

Hayter, R. (1997). The dynamics of industrial location: The factory, the firm and the production system. New York: Wiley.

Krugman, P. (1995). Development, geography, and economic theory. Cambridge, M.A.: The MIT Press.

Machlup, F. (1967), Theories of the firm: Marginalist, behavioral, and managerial. American Economic Review, 57, 1-33.

McCann, P. (Ed.). (2002). Industrial location economics. Edward Elgar. Cheltenham, UK; Northampton, M.A., USA.

McDonald, A. L. (1986). Of floating factories and mating dinosaurs. Harvard Business Review, 64(6), 82-86.

Mohamed, Z. M., \& Youssef, M. A. (2004). A production, distribution and investment model for a multinational company. Journal of Manufacturing Technology Management, 15(6), 495-510.

Parr, J. (2002). The location of economic activity: Central place theory and the wider urban system. In P. McCann (Ed.), Industrial location economics (pp. 32-82). Camberley: Edward Elgar.

Pen, C. J. (1999). Improving behavioral location theory: Preliminary results of a written questionnaire decision making of firm relocations. Presented at the European Regional Science Association Congress, Dublin.

Storper, M., \& Walker, R. (1989). The capitalist imperative: Territory, technology, and industrial growth. Oxford, UK: Basil Blackwell.

Ženka, J., \& Cadil, V. (2009). Regional distribution of technology intensive manufacturing industries in the Czech Republic with an accent on risk of delocalization. Prague Economic Paper, 1, 61-77. 